\title{
Impact of Public Expenditure on Climate Change in Nigeria: Lessons from South Africa
}

\author{
${ }^{*}$ Ogujiuba Kanayo ${ }^{1}$, Stiegler Nancy ${ }^{1}$, Terfa W. Abraham ${ }^{2}$ \\ ${ }^{1}$ University of Western Cape; Cape Town-South Africa \\ ${ }^{2}$ National Institute for Legislative Studies Abuja, Nigeria \\ *kannyog@gmail.com
}

\begin{abstract}
This paper examines the role of public expenditure in enhancing climate change adaptation and mitigation in Nigeria. It examines the trend of carbon dioxide $\left(\mathrm{CO}_{2}\right)$ in Nigeria alongside those of South Africa and Sub Saharan Africa and investigates the statistical relationship between public expenditure and climate change in Nigeria. The paper hinges on the Climate Public Expenditure and Institutional framework of the Oversee Development Institute (ODI), which argues that climate change, has fiscal implications and can be addressed using national plans and annual budgets. Time series data were then collected for emission, public expenditure, human development index and economic growth from the World Bank and the Central Bank of Nigeria for 1970-2008, while trend analysis and lag regression model were used for data analysis. It was found that public expenditure towards economic services could be used to enhance Nigeria's climate change mitigation and adaptation strategies. Though economic growth and human development index were found to be positively related to emission, results imply that economic growth in Nigeria is not pursued in a sustainable manner that accounts for the future generation. The paper recommends that economic growth that is driven by investment in renewable energy, developing human capacity to adapt to climate change and coordinating public expenditure to economic and community services to develop rural communities and vulnerable sectors like agriculture, would be useful for addressing climate change in Nigeria and ensuring sustainable development. A lesson Nigeria can learn from climate change mitigation and adaptation measures in South Africa is to identify and prioritize short term and medium term adaptation interventions to be addressed in sector plans such as water, agriculture and forestry, health, biodiversity and human settlements.
\end{abstract}

Key words: Climate Change, Adaptation, Mitigation, National Plan, Budget

\section{Introduction}

Nigeria's current development plan is embedded in the Nation's Vision 20:2020 programme (NPC, 2009). The nation's transformation agenda and the global Millennium Development Goals (MDGs) also seek to achieve certain targets by 2015 (UNDP, 2003 and NPC, 2011). For instance, the MDGs one, three, five and seven are to eradicate extreme poverty and hunger; promote gender equality and empower women; improve maternal health; and ensure environmental sustainability by 2015 respectively, while the key macroeconomic policy choices of Nigeria's transformation agenda includes reviewing the budget process to among other things, concentrate on setting allocation priorities; and institutionalizing the culture of development planning at all levels of government and to ensure that annual capital budget allocations take a cue from the medium and long term development plans. However, the success of achieving these goals would very much involve addressing climate change as poverty and hunger for instance can be aggravated due to climate change (Reid and Huq, 2007). Agricultural activities in Nigeria are concentrated in rural communities and have vulnerable groups (women and children) as the larger segment of its workforce. Extreme weather events (flood and drought) would therefore lead to loss of farmlands and agricultural output, which would in turn, lead to increase poverty, hunger, and vulnerability to sickness and diseases. As contained in the Nigerian transformation agenda programme therefore, reviewing the budget process towards setting allocation priorities and ensuring that annual capital budget allocation are consistent with medium and long-term development plans in Nigeria however, would help in improving the ability of vulnerable groups and communities to mitigate and adapt to climate change. The impact of climate change on various aspects of economy and society has been the subject of various studies in recent times (see GCCA, 2011 and CDDE, 2011) and policy discourse as well seem to be shifting towards building short run and long run mitigation and adaptation strategies to mitigate climate change impacts on overall development using national development plans (CEPS and ZEW, 2010; and ODI and CDDE, 2011). Why the debate is between whether the use of public expenditure should be on cross-government basis (CDDE, 2011) or on national government basis (ODI and CDDE, 2011), country specific studies are required to provide empirical evidence for ascertaining the potency of 
public expenditure and climate change policy. The paper therefore raises the following research questions: (1) Can public expenditure be used to enhance climate change mitigation and adaptation in Nigeria? In addition (2) what are the experiences from countries that are affected by climate change in Africa? The objectives of the paper therefore are to examine the role of public expenditure on climate change mitigation and adaptation in Nigeria; and to draw experience from South Africa on climate change mitigation and adaptation.

\section{Literature Review}

New and additional international finance is becoming available to assist country efforts in their response to climate change. Referred to as the Climate Fiscal Framework by the CCDE (2011), the ODI and CDE (2011:2) argued that what is important however is a framework on how this finance could be integrated into national policy, planning and budgetary systems of cross-governments. As argued by the ODI and CDDE (2011), the challenge however, is to secure a comprehensive, cross-government approach that would deliver a coherent national response to climate change that would involve both the public and private sectors. This approach however does not recognize the individual role of national government to act alone in this direction. This is important, as specific national success of building in climate change adaptation and mitigation strategies into national plans is essential before cross-government collaboration would be feasible. The ODI and CDDE (2011) therefore argued that the first step in building a Climate Fiscal Framework would be to develop a methodology that reviews how climate change-related expenditures are integrated into national budgetary processes: one that is termed Climate Public Expenditure and Institutional Review by the ODI and CDDE (2011: 2). The ODI and CDDE however argue that the framework has to be set within the context of the national policy and institutional arrangements that exist to manage the response to climate change in each country. The institutional arrangement for climate change response in Nigeria however, is however not clear-cut. The National Climate Change Commission Bill is yet to be made law. Present efforts to address emergency cases relating to natural and other disasters is vested with the National Emergency Management Agency (NEMA), while policy coordination is located within the ambit of the Ministry for the Environment. This environmental gap imposes policy management. The centre for European Policy Studies (CEPS) and Centre for European Economic Research (ZEW) have however argued that the link between climate change adaptation and national budgets have not been given adequate attention in the literature. They called for further studies linking climate change and national budgets especially in countries where the negative impacts caused by climate change are strongest (CEPS and ZEW, 2010). Nigeria relies heavily on crude oil exploration and exports for over 80 percent of its revenue. Despite the potential of the agricultural sector to diversify the nation's revenue sources, the sector is however still concentrated in the rural communities, agricultural (farm) output still follows rain, and dry season circles (Abraham, 2011). Annual budgets therefore, could be used to enhance the capacity of vulnerable sectors of the economy to mitigate climate change and build adaptation strategies. The present paper is also consistent with the arguments of the GCCA (2011) that integrating climate change issues into the budgetary process would be important for enhancing climate change mitigation and adaptation strategies as it would provide funds to finance mitigation and adaptation plans for vulnerable sectors.

\section{Methodology}

Data: Secondary data was collected for $\mathrm{CO}_{2}$ emission, gross domestic product and federal government capital expenditure on community services from 1970 to 2008. Trend analysis and distributed lag model is then used for the analysis. To identify lessons for Nigeria, a review of measures for climate change adaptation and mitigation in South Africa is also presented. The data used for the paper are secondary data collected from the World Bank and the Central Bank of Nigeria (CBN) statistical bulletin for the period 1970 to 2008. The reason for 1970 to 2008 is based on World Bank data availability for $\mathrm{CO}_{2}$ in Nigeria that is available for up to 2008, while the choice of 1970 is attributable to the rapid expansion in public spending in Nigeria due to the soaring of crude oil price in the international market. Nigeria's carbon dioxide $\left(\mathrm{CO}_{2}\right)$ emission as proxy for climate change/global warming was collected from the World Bank climate change database while Nigeria's data on public (capital) expenditure on community and economic services; and gross domestic product (GDP) as proxy for economic growth were collected from the CBN statistical bulletin. The data on Human Development Index (HDI) was collected from the World Economic Fact Book, 2009 and UNDP Human Development Report 2007/2008 
Procedure: To analyze the data, the paper used lag regression model in other to provide for medium term adjustment that is required from capital budget on economic and community services, economic growth and human development to mitigate climate change. The model is specified below:

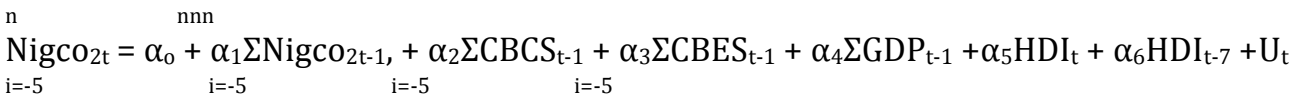

Where $\mathrm{NIGCO}_{2}$ is Nigeria's $\mathrm{CO}_{2}$ emission, $\mathrm{CBCS}$ is federal government capital expenditure to community services, CBES is federal government capital expenditure to economic services, GDP is Nigeria's gross domestic product, HDI is Nigeria's human development index and $U_{t}$ is the error term. While CBCS and CBES are the direct variables that capture capital public expenditure in the model, the distributed lag values for $\mathrm{NigCO}_{2}$ are used as proxy for $\mathrm{CO}_{2}$ mitigation and adaptation. Economic growth was included because countries still need to grow despite climate change. Therefore, understanding the relationship that their growth has on $\mathrm{CO}_{2}$ emission would also be important for mitigating climate change impacts. HDI is introduced in the equation as a control variable because it measures literacy rate, per capita income and life expectancy. Thus, introducing this variable as a control allows policy makers to measure the role of human development in mitigating the anthropogenic dimensions of climate change as well. The variables were logged and then tested for stationary. All the variables were found to non-stationary at levels but became stationary at first difference. The model is estimated using E-views econometric package.

\section{Results and Discussion}

Trend Analysis of $\mathrm{CO}_{2}$ Emission in Nigeria, South Africa and SSA: According to the World Bank data, Nigeria's $\mathrm{CO}_{2}$ emission peak was in 1974 with 0.983075 metric tons per capita of $\mathrm{CO}_{2}$, while for South Africa it was in 1984 with a figure of 10.35715 metric tons per capita of $\mathrm{CO}_{2}$. The minimum value for Nigeria however was in 1962 with a figure of 0.0872077 metric tons per capita. For South Africa however, the minimum emission year over the sample period was 1961 at 5.694383. Looking at the trend of emission for South Africa and Nigeria, statistics shows that South Africa has made effort to stabilize its $\mathrm{CO}_{2}$ emission since the adoption of the Kyoto protocol in 1997 by 37 countries $^{1}$ while that of Nigeria has remained volatile. Although South Africa ratified ${ }^{2}$ the Kyoto protocol on the 31 July 2002, the deduction here is that South Africa compared to Nigeria, has contributed to global efforts to cut down emission than Nigeria. Differencing both trends reveals the volatility in their emission rate over time.

Figure 1: CO2 Emission in South Africa and Nigeria: 1961 - 2008
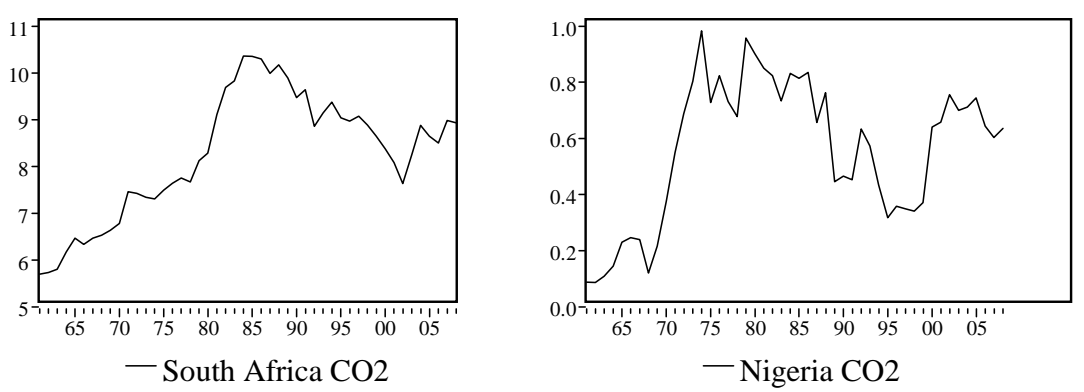

\footnotetext{
${ }^{1}$ Australia, Austria, Belarus, Belgium, Bulgaria, Canada, Croatia, Czech Republic, Denmark, Estonia, Finland, France, Germany, Greece, Hungary, Iceland, Ireland, Italy, Japan, Latvia, Liechtenstein, Lithuania, Luxembourg, Malta, Monaco, Netherlands, New Zealand, Norway, Poland, Portugal, Romania, Russian Federation, Slovakia, Slovenia, Spain, Sweden Switzerland, Turkey, Ukraine, United Kingdom and United States of America
}

\footnotetext{
${ }^{2}$ The Protocol was initially adopted on 11 December 1997 in Kyoto, Japan, and entered into force on 16 February 2005. As of September 2011, 191 states have signed and ratified the protocol. South Africa ratified the agreement on the 31 July 2002 , while Nigeria ratified the agreement on the 10 December 2004. Signing is optional, indicating an intention to ratify the Protocol. Ratification means that an Annex I party (e.g. a developed country or one with an 'economy in transition') has agreed to cap emissions in accordance with the Protocol. 38 of the 39 Annex I parties have agreed to cap their emissions in this way, two others are required to do so under their conditions of accession into the EU, and one more intends to become an Annex I party.
} 

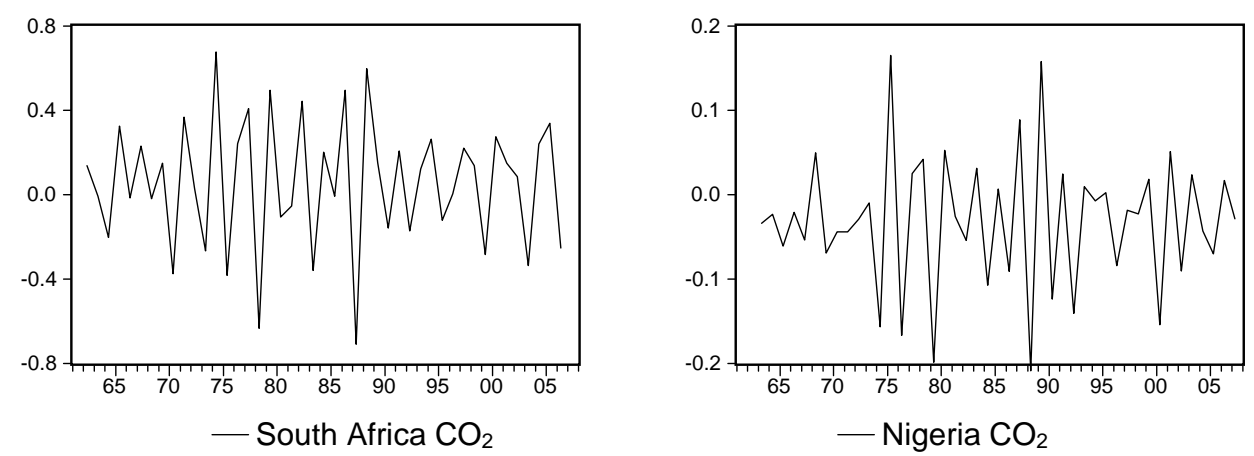

Source: Authors presentation

The differenced trend for Nigeria has very high spikes that touch the upper and lower plane of the box. The spikes for South Africa however is some worth concentrated around the origin of the graph. This further confirms that policy efforts are being made in South Africa to stabilize $\mathrm{CO}_{2}$ emission rates unlike that of Nigeria that seems not to. Putting the South African $\mathrm{CO}_{2}$ emission side by side with the $\mathrm{CO}_{2}$ emission for Sub Saharan Africa reveals almost a similar pattern in their trend (see Figure 3 below). This implies that South Africa is a significant polluter in the region. However, addressing climate change should be done by all countries since climate is a global 'public' good.

\section{Figure 3: C02 Emission for Sub Saharan Africa and South Africa Compared}

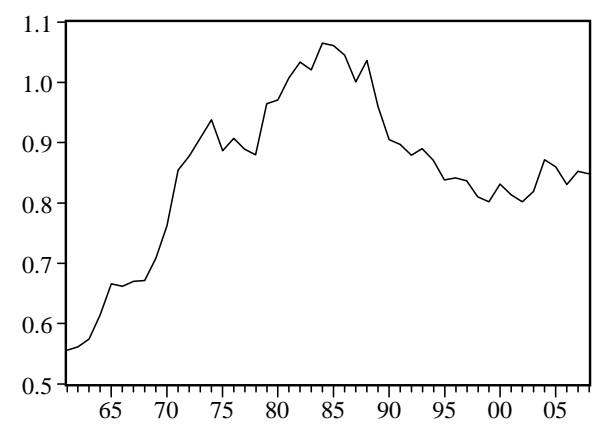

- Sub Saharan Africa CO2

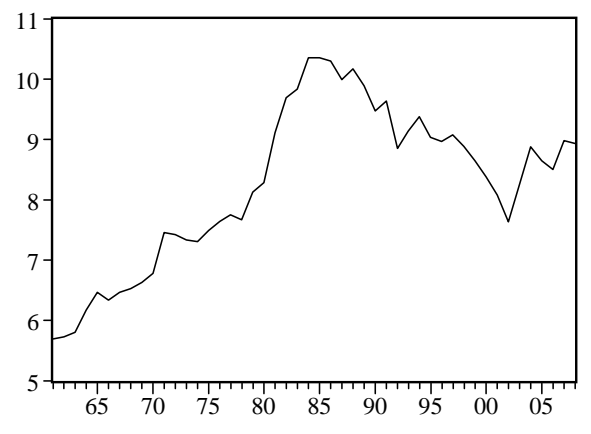

- South Africa CO2

Source: Authors presentation

A major difference between both trends is that while for South Africa, there was a major deep in $\mathrm{CO}_{2}$ emission since the 1997 Kyoto protocol, the average for Sub Saharan Africa, does not seem so. This suggests that South Africa's effort to cut down emission significant drives down carbon emission in Sub Saharan Africa. However, since collective efforts are required to bring down global emission, every African country should support the global course to cut down emission. Besides, increased extreme events (especially floods and drought) in Nigeria have in recent times, led to the destruction of life's, properties and farmlands. This would require huge construction projects (through increased capital budgeting from both the states and federal government) to contain floods and rising river levels along the coastal areas of Southern Nigeria, River Niger, River Benue and the Kaduna River.

Econometric Analysis: The dynamic relationship between $\mathrm{CO}_{2}$ emission, capital public expenditure (to community and economic services), gross domestic product, and human development was estimated using a lagged regression model. The result is presented in Table 4.1 below. 
Table 1: Result of the Estimated Model

\begin{tabular}{|c|c|c|c|c|}
\hline \multicolumn{5}{|c|}{ Dependent Variable: NIGCO2 } \\
\hline \multicolumn{5}{|c|}{ Method: Least Squares } \\
\hline \multicolumn{5}{|c|}{ Sample(adjusted): 19702008} \\
\hline \multicolumn{5}{|c|}{ Included observations: $\mathbf{3 1}$ after adjusting endpoints } \\
\hline Variable & Coefficient & Std. Error & t-Statistic & Prob. \\
\hline $\mathrm{C}$ & -0.139084 & 0.035421 & -3.926639 & 0.0111 \\
\hline NIGCO2(-1) & 0.992555 & 0.342322 & 2.899479 & 0.0338 \\
\hline NIGCO2(-2) & -0.313915 & 0.240354 & -1.306054 & 0.2484 \\
\hline NIGCO2(-3) & -0.159381 & 0.137128 & -1.162273 & 0.2976 \\
\hline NIGCO2(-4) & -0.476672 & 0.143437 & -3.323219 & 0.0209 \\
\hline NIGCO2(-5) & 0.670522 & 0.179023 & 3.745444 & 0.0134 \\
\hline CBCS & -0.062428 & 0.071793 & -0.869555 & 0.4243 \\
\hline CBCS(-1) & 0.040300 & 0.090409 & 0.445751 & 0.6744 \\
\hline CBCS(-2) & 0.306979 & 0.098166 & 3.127130 & 0.0260 \\
\hline $\operatorname{CBCS}(-3)$ & 0.102288 & 0.083255 & 1.228613 & 0.2739 \\
\hline $\operatorname{CBCS}(-4)$ & -0.051219 & 0.073124 & -0.700447 & 0.5149 \\
\hline $\operatorname{CBCS}(-5)$ & 0.094733 & 0.057548 & 1.646153 & 0.1607 \\
\hline CBES & -0.260814 & 0.064495 & -4.043925 & 0.0099 \\
\hline CBES(-1) & 0.131174 & 0.075853 & 1.729312 & 0.1443 \\
\hline CBES(-2) & -0.197909 & 0.071370 & -2.773017 & 0.0392 \\
\hline CBES(-3) & 0.232138 & 0.091436 & 2.538803 & 0.0520 \\
\hline CBES(-4) & -0.384522 & 0.107758 & -3.568373 & 0.0161 \\
\hline CBES(-5) & 0.107028 & 0.069338 & 1.543555 & 0.1833 \\
\hline GDP & 0.423693 & 0.153450 & 2.761123 & 0.0398 \\
\hline GDP(-1) & 0.010247 & 0.145368 & 0.070493 & 0.9465 \\
\hline GDP(-2) & -0.256150 & 0.181096 & -1.414444 & 0.2164 \\
\hline GDP(-3) & 0.232662 & 0.163266 & 1.425048 & 0.2135 \\
\hline GDP(-4) & 0.280415 & 0.165323 & 1.696162 & 0.1506 \\
\hline GDP(-5) & 0.327107 & 0.131138 & 2.494376 & 0.0549 \\
\hline HDI & 1.720463 & 0.819180 & 2.100225 & 0.0897 \\
\hline HDI(-7) & 6.051339 & 1.816552 & 3.331223 & 0.0208 \\
\hline $\mathrm{R}$-squared & 0.968627 & Mean dep & ndent var & -0.001970 \\
\hline Adjusted R-squared & 0.811759 & S.D. depe & dent var & 0.087187 \\
\hline S.E. of regression & 0.037828 & Akaike info & riterion & -3.858677 \\
\hline Sum squared resid & 0.007155 & Schwarz & iterion & -2.655978 \\
\hline Log likelihood & 85.80949 & F-statisti & & 6.174819 \\
\hline Durbin-Watson stat & 1.589869 & Prob(F-stat & tic) & 0.025826 \\
\hline
\end{tabular}

Source: Authors Estimation (E-views Output)

The variables were lagged to 5 years to see the distributed impact of public expenditure, economic growth and efforts to reduce $\mathrm{CO}_{2}$ on current emission, while human development index was used as the control variable to simulate the length of investment in human capital that would reduce the anthropogenic cause of climate change in Nigeria. The result shows that higher rates of human development index, which is made up of literacy rate, per capita income and life expectancy, contributes to increased $\mathrm{CO}_{2}$ emission in Nigeria. This implies that the quality of human development in Nigeria directly contributes to $\mathrm{CO}_{2}$ emission. This can be seen through their $\mathrm{CO}_{2}$ emitting consumption pattern such as in the use of generators, automobiles, among others that emit green house gasses. The current value of Gross domestic product and its value at lag 5 are positively related to Nigeria's $\mathrm{CO}_{2}$. This implies that green house gas emission accompanies Nigeria's growth. In the words of the World Commission on Environment and Development (WCED) (1987), this is an indication that growth in Nigeria is not pursued in a sustainable manner that would meet the present needs of the people without compromising the ability of the future generations to meet their own needs. Capital public expenditure was divided into two: capital expenditure to community services (CBCS) and to economic services (CBES). For CBCS, its normal value and value at lag 4 had a negative impact on Nigeria's $\mathrm{CO}_{2}$ implying that capital budget allocation on community services for a period of one to four years can be used to enhance Nigeria's adaptation and mitigation capacities. The result however was not significant which suggests that, the effectiveness of CBCS in addressing climate change would require more than a short term framework to achieve significant results. The coefficient at lag 2 however was positive and significant. This implies that 
the direction on which capital budget on community services was spent over the years have contributed to increased emission in Nigeria. This could imply spending on equipments that emit green house gases and not funding enlightenment programme that educate people of the impact of their anthropogenic activities on the environment and climate change. The positive impact of $\mathrm{HDI}$ on $\mathrm{CO}_{2}$ emission also implies that, as individuals become more literate, gain higher incomes and live longer in Nigeria, $\mathrm{CO}_{2}$ emission increases. This is seen with $\mathrm{CO}_{2}$ emitting cars/vehicles, electricity generators among others.

Educating the populace on the need to cut on such consumption habits and complimenting them with cycling, short distance trekking, use of low energy consuming electrical bulbs among others, would be useful to addressing climate change impacts. The coefficient for capital expenditure to economic services however was negative and significant at lag 2 and 4. This implies that increasing capital expenditure on economic services could be used support measures aimed at addressing climate change in Nigeria. The components of capital expenditure to economic services are agriculture, construction, transport and communication, and other economic services. These sectors are very prone to climate change. Agriculture output for instance is prone to climate variability, which could lead to low crop yield and eroding of farmlands. Channelling capital expenditure into projects that would help address these issues would therefore help to reduce the impact of climate change in Nigeria. Construction activities in rural areas have led to land grab and rapid deforestation. Channelling capital budgets into a forestation projects and construction of drainage systems therefore, could be used to address climate change in Nigeria. For transportation, capital expenditure could be used to fund renewable energy such as coal and low carbon emitting energy sources. In the rural areas, women engage in tree felling for use as firewoods, which contributes to deforestation. The provision of coal for instance, could help in preserving trees/forest thus, reducing erosions and the impact of water run-offs on land surface. Most rural areas have poor communication networks ranging from telecommunication to internet facilities. While telecommunication industries base their provision of network in rural areas on market driven principles, the government could help in providing networks in difficult to reach areas. This would help affected communities to communicate with appropriate authorities/agencies when they are faced with climate risk and disasters. The need to cut down emission in Nigeria and improving on adaptation strategies is reiterated by the lag values of $\mathrm{CO}_{2}$ regressed on its present values. $\mathrm{CO}_{2}$ emission coefficient at lag 1 is positively related to the dependent variable: an evidence that mitigation efforts in the previous year is not strong enough to reduce present day emission.

Further, at lag 4 however, the coefficient was negative and significant implying that efforts to address climate change are implemented over time; they get more effective in reducing emission and mitigating climate change impact in Nigeria. The result however, was unstable since the impact of $\mathrm{CO}_{2}$ at lag 5 was found to have a positive relationship with the dependent variable (i.e. $\mathrm{CO}_{2}$ at current level). Generally, the model had a good fit as shown by the F-statistic, which is significant at 5 percent critical value, the value of adjusted R-square, which is at 81.17 percent and the Durbin-Watson statistic that is approximately 2 . However, the results are based on a single country (i.e. Nigeria) and the results obtained from the paper should be taken with caution as the availability of wider datasets and the use of alternative models could yield different results. Simulation done using computable general equilibrium models for instance could yield other results and spell out a wider range of the fiscal adjustment required for all sectors in other to enhance climate change mitigation and adaptation strategies for Nigeria. In summary therefore, public expenditure through capital budget can be used to enhance Nigeria's climate change mitigation and adaptation strategies especially through public capital expenditure to economic services, which includes agriculture, construction, transport and communication, and other economic services. Efforts should also be made to orientate the population to move away to consumption patterns that increases green house gases into cleaner modes of consumption. This is based on the finding that human development index has a positive relationship with $\mathrm{CO}_{2}$ emission implying that, as literacy rate, per capita income and life expectancy improves in Nigeria, people tend to form a consumption pattern that contributes to green house gas emission. Thus, there is also a need for the national orientation agency to engage in public enlightenment to help people appreciate the merits of forming greener habits of consumption.

Lessons from South Africa: As contained in Nigeria's vision 2020 framework, Nigeria seeks to be the world's $20^{\text {th }}$ economy by year 2020: a position South Africa currently occupies. Among other things that needs to be done by Nigeria therefore is to address climate change issues through effective policy formulation as South Africa is doing and even more given Nigeria's position as significant oil producer in Africa. The lessons Nigeria can learn from climate change mitigation and adaptation measures in South Africa as it relates to rural communities is to identify and prioritize short term and medium term 
adaptation interventions to be addressed in sector plans. The following sectors where identified in the white paper: water, agriculture and forestry, health, biodiversity and human settlements. Rural communities in many states in Nigeria do not have clear hydrological systems that channels precipitation runoff to storage systems. Because of the absence of the storage systems, rural communities result to the use of pounds, which are usually contaminated through surface run offs and constitute health hazard to the populace. Through capital budget to community services, good hydrological systems can be built or constructed to address such problems. It should also be noted that, urban slums can that do not have water drainage systems are also susceptible to health hazard from extreme rainfall. It could also lead to collapse of structures/buildings and flooding in the area. Thus, the identification of human settlements that are susceptible to the vagaries of climate change would help to channel capital budget to community services to more effective use of climate change adaptation. For mitigation, the key elements of South Africa's approach to climate change mitigation include: (1) using a National GHG Emissions Trajectory Range, against which the collective outcome of all mitigation actions will be measured; (2) defining desired emission reduction outcomes for each significant sector and sub-sector of the economy based on an in-depth assessment of the mitigation potential, best available mitigation options, science, evidence and a full assessment of the costs and benefits; (3) Adopting a carbon budget approach to provide for flexibility and least-cost mechanisms for companies in relevant sectors and/or sub-sectors and, where appropriate, translating carbon budgets into company level desired emission reduction outcomes; and (4) Requiring companies and economic sectors or sub-sectors for which desired emission reduction outcomes have been established to prepare and submit mitigation plans that set out how they intend to achieve the desired emission reduction outcomes. Since rural communities engage in tree felling for energy purpose, alternative energy can be provided to cut down anthropogenic activities that contribute to deforestation and heating of the earth surface.

\section{Conclusion and Recommendations}

This paper examined the role of public expenditure in enhancing climate change adaptation and mitigation in Nigeria. The paper hinges on the Climate Fiscal Framework of the CCDE (2011) and the Climate Public Expenditure and Institutional framework of the ODI and CDDE (2011). Both frameworks see the need for governments to build in their climate change mitigation and adaptation efforts into their national plans and budgetary process. The results found indicated that public expenditure to economic services (which is composed of agriculture, construction, transport and communication and other economic services) can be used to enhance Nigeria's climate change mitigation and adaptation strategies. Though economic growth and human development index were found to be positively related to emission, it implied that green house gas emission accompanies Nigeria's growth and indicates that growth in Nigeria is not pursued in a sustainable manner that would meet the present needs of the people without compromising the ability of the future generations to meet their own needs. Government programmes that would enlighten the people on the need to turn away from anthropogenic activities that contributes to climate change like tree felling and forming consumption patterns that are tilted towards encouraging renewable energy sources would be vital. Public (capital) expenditure should also be used to carry out projects in the vulnerable communities. This could include constructing water runways that could channel floods to high capacity reservoirs for instance. The conclusion deduced from this paper however, are based on results obtained for Nigeria and should not be generalized for other countries as mitigation and adaptation strategies depend on how countries are exposed to vagaries of climate change. Yet for Nigeria, further studies, with wider data sets and system wide simulation analysis should be conducted to confirm the plausibility of the finding established in this paper. The findings and conclusion should therefore be taken with a pinch of salt. 


\section{References}

Abraham, T. W. (2011). Climate Change and Food Supply in Nigeria', Nigerian Economic Society (NES) $52^{\text {nd }}$ Conference on Planning and the Transformation of the Nigerian Economy, Covenant University, Nigeria, 13-15 September

CDDE (2011). Climate Fiscal Frameworks: Improving the Effectiveness of Climate Finance at the Country Level. Draft guidance note of the Capacity Development for Development Effectiveness (CDDE) 29th August, Bangkok.

CEPS \& ZEW (2010). The Fiscal Implications of Climate Change Adaptation' Final Report (August 12) of the Centre for European Policy Studies (CEPS) and the Centre for European Economic Research (ZEW).

GCCA (2011). Mainstreaming Climate Change in the Budgetary Process' A Publication of the Global Climate Change Alliance (GCCA).

IIED (2007). Adaptation to Climate Change: How we are set to cope with the impacts- An International Institute for Environment and Development (IIED) Briefing.

IPCC (2007). Climate Change 2007: Impacts, Adaptation and Vulnerability. Summary for Policymakers. Working Group II Contribution to the IPCC Fourth Assessment Report.

Ministry of Finance. (2009). Ministry of Finance Green Paper: Economic and Fiscal Policy Strategies for Climate Change Mitigation in Indonesia, Ministry of Finance and Australia Indonesia Partnership, Jakarta.

NPC (2009). Nigeria Vision 20:2020 Economic Transformation Blueprint' A Publication of the National Planning Commission (NPC) of the Federal Republic of Nigeria (FGN), October

NPC (2011). The Transformation Agenda of the Federal Republic of Nigeria (2011-2015)' A Publication of the National Planning Commission (NPC) of the Federal Republic of Nigeria (FGN).

ODI \& CDDE (2011). Climate Public Expenditure and Institutional Review: A Methodology to Review Climate Policy, Institutions and Expenditure' Working Paper of the Over Development Institute (ODI) and the Capacity Development for Development Effectiveness (CDDE).

Reid, H. \& Huq, S. (2007). Adaptation to Climate Change: How we cope with the impacts An International Institute for Environment and Development (IIED) Briefing.

The Government of the Republic of South Africa. (2011). National Climate Change Response White Paper October.

UNDP (2003). Human Development Report 2003: Millennium Development Goals - A compact among Nations to End Human Poverty. New York: Oxford University Press for the United Nations Development Programme.

WCED (1987). our common future Oxford, UK: World Commission on Environment and Development (WCED), Oxford University Press. 